\title{
Peripheral nerve block with phenol to treat spasticity in spinal cord injured patients
}

\author{
S Gündüz MD, T A Kalyon MD, H Dursun MD, H Möhür MD, F Bilgiç MD \\ The Department of Physical Therapy and Rehabilitation, Gülhane Military Medical \\ Academy, Etlik, Ankara 06018, Turkey.
}

\begin{abstract}
In this study an attempt was made to treat spinal cord injured patients with severe spasticity by peripheral nerve blocks. Thirty-six patients ( 5 female, 31 male) ranging in age from 20 to 71 years (mean: 29 $\mp 8.2$ ) were treated by phenol injections. A specially designed electrostimulation needle was used for the injections. The results showed that peripheral nerve blocks with phenol solution could be a remedy on a temporary basis, but are not as effective as has been described previously.
\end{abstract}

Keywords: spinal cord injury; spasticity; peripheral nerve block; phenol.

\section{Introduction}

Spasticity is a term widely used by clinicians to describe certain abnormalities in patients with lesions of the central nervous system (CNS), but the signs and symptoms found in such patients vary widely from patient to patient as does the response to any given therapy. Spasticity is a motor disorder characterised by a velocity dependent increase in tonic stretch reflexes (muscle tone) with exaggerated tendon jerks, resulting from hyperexcitability of the stretch reflex; but the definition excludes other features of spasticity (such as flexor spasms, weakness and loss of dexterity) with lesions affecting the spinal cord, brain stem or cerebral hemispheres. ${ }^{1}$ Spasticity is a common complication of patients with spinal cord injury. Maynard and colleagues found that $67 \%$ of SCI patients exhibited spasticity. ${ }^{2}$

Although spasticity is sometimes felt to be useful for a patient, it often interferes with physical activity, interrupts sleeping patterns, leads to contractures and limits the degree of independence. Thus treatment is usually desirable but it is difficult to treat spasticity successfully. Drugs, mainly baclofen, diazepam and dantrolen are not uniformly helpful and can have systemic side effects, such as confusion, hallucina- tions, sedation, hypotonia, ataxia and even hepatotoxicity. To avoid these undesirable side effects, phenol injections for either a peripheral nerve block or motor point injections can be used. The principal purpose of phenol injections is to provide a temporary reduction in spasticity.

In this study we aimed to assess the effectiveness of peripheral nerve blocks with phenol, and also to determine the duration of spasticity in patients with spinal cord injury.

\section{Patients and methods}

Fifty peripheral nerves in 36 patients were treated with phenol injections. There were 5 females and 31 males ranging in age from 20 to 71 (mean: $29 \mp 8.2$ ). All had had a traumatic spinal cord injury. Subjects were divided into three levels of injury: cervical, thoracic and lumbar. They were also evaluated by the degree of the lesion, as being complete or incomplete (Table I). Of the 36 patients, 12 had pressure sores, 8 had indwelling urethral catheters, 4 were on intermittent catheterisation, 16 were on condom drainage, and the remainder voided urine voluntarily.

Spasticity was considered to be present in 
Table I Neurological level

\begin{tabular}{lccc}
\hline Categories & Complete & Incomplete & Total \\
\hline Cervical & 8 & 6 & 14 \\
Thoracic & 10 & 8 & 18 \\
Lumbar & 2 & 2 & 4 \\
Total & 20 & 16 & 36 \\
\hline
\end{tabular}

Table II Definition of Ashworth scores

\begin{tabular}{ll}
\hline Grade & Degree of muscle tone \\
\hline 1 & $\begin{array}{l}\text { No increase in tone } \\
\text { Slight increase in tone, minimal } \\
\text { resistance at the end of movement } \\
\text { in the affected part }\end{array}$ \\
3 & $\begin{array}{l}\text { More marked increase in tone but } \\
\text { affected part easily flexed } \\
\text { Considerable increase in tone; } \\
\text { passive movement difficult } \\
\text { Affected part rigid in flexion or } \\
\text { extension }\end{array}$ \\
\hline
\end{tabular}

patients who had increased deep tendon reflexes, increased muscle tone during passive movements, and/or involuntary muscle spasms. Spasticity was graded from 1 to 5 using the Ashworth scale (Table II). A DISA Type 14 El stimulator unit and a DISA Type C12 EMG amplifier were used as an electrical source. A 2.5 inch needle coated with teflon was used. The cathode of the stimulator was connected to the needle and the anode was connected to a surface electrode. An injection was made when maximum contraction was obtained in the related muscle or muscle groups by electrostimulation. A $5 \%$ aqueous solution of phenol was used, in a volume of $2 \mathrm{ml}$ to $3 \mathrm{ml}$.

\section{Results}

Fifty peripheral nerve blockages were carried out. The peripheral nerves selected were as follows: 34 obturator nerves, 11 sciatic nerves and 5 femoral nerves (Table III). Assessments were made at the first week, and at the first and second months (Tables IV, V, VI). Degrees of 2 and 3 were taken to be acceptable. Statistical analysis was made by the Friedman test computed by a software programme. Descriptive values regarding the differences are given in Table VII. One patient developed cutaneous anaesthesia after injection but it vanished by the nineteenth day.

\section{Discussion}

Khalili and his colleagues ${ }^{3}$ advocated peripheral nerve blocks with phenol, and considered that the ideal means of management

Table III Peripheral nerves injected

\begin{tabular}{|c|c|c|c|c|c|c|c|}
\hline \multirow[t]{2}{*}{ Nerve } & \multicolumn{3}{|c|}{ Primary block } & \multicolumn{3}{|c|}{ Repetition of block } & \multirow[t]{2}{*}{ Total } \\
\hline & Total & Right & Left & Total & Right & Left & \\
\hline Obturator & 34 & 19 & 15 & 7 & 3 & 4 & 41 \\
\hline Sciatic & 11 & 5 & 6 & 1 & - & 1 & 12 \\
\hline Femoral & 5 & 3 & 2 & - & & & 5 \\
\hline Total & 50 & & & 8 & & & 58 \\
\hline
\end{tabular}

Table IV Results at the end of the first week

\begin{tabular}{|c|c|c|c|c|c|}
\hline Initiation & Grade 5 & Number & Grade 4 & Number & Total \\
\hline One week & Grade 2 & 21 & Grade 2 & 7 & 28 \\
\hline \multirow[t]{3}{*}{ later } & Grade 3 & 10 & Grade 3 & 2 & 12 \\
\hline & Grade 4 & 4 & Grade 4 & 2 & 6 \\
\hline & Grade 5 & 4 & Grade 5 & - & 4 \\
\hline Total & & 39 & & 11 & 50 \\
\hline
\end{tabular}

$\overline{\mathrm{x}}=2.720 \mp 0.137, p<0.01$ 
Table V Results at the end of the first month

\begin{tabular}{lccccc}
\hline Initiation & Grade 5 & Number & Grade 4 & Number & Total \\
\hline One month & Grade 2 & 17 & Grade 2 & 4 & 21 \\
later & Grade 3 & 10 & Grade 3 & 2 & 12 \\
& Grade 4 & 5 & Grade 4 & 5 & 10 \\
Total & Grade 5 & 7 & Grade 5 & - & 7 \\
\hline
\end{tabular}

$\overline{\mathrm{x}}=3.060 \mp 1.155, p<0.01$

Table VI Results at the end of the second month

\begin{tabular}{lccccc}
\hline Initiation & Grade 5 & Number & Grade 4 & Number & Total \\
\hline 2 months & Grade 2 & 12 & Grade 2 & 1 & 13 \\
later & Grade 3 & 7 & Grade 3 & - & 7 \\
& Grade 4 & 12 & Grade 4 & 8 & 20 \\
Total & Grade 5 & 8 & Grade 5 & 2 & 10 \\
\hline
\end{tabular}

$\overline{\mathrm{x}}=3.540 \mp 0.154, p<0.01$

Table VII Descriptive values

\begin{tabular}{|c|c|c|c|c|}
\hline & $\mathrm{N}$ & $\begin{array}{c}\overline{\mathbf{x}} \\
\text { mean }\end{array}$ & $\mp$ & $\mp S \bar{x}$ \\
\hline Before & 50 & 4.72 & & 0.0949 \\
\hline 1 week & 50 & 2.72 & & 0.137 \\
\hline 1 month & 50 & 3.06 & & 0.155 \\
\hline 2 month & 50 & 3.54 & & 0.154 \\
\hline
\end{tabular}

was a quantitative and long lasting alleviation of spasticity in a selected group of muscle fibres without impairment of sensation and voluntary movement or local and systemic side effects. Awad made a major contribution to this topic. ${ }^{4}$ The procedure has been performed on hemiplegic patients. ${ }^{5-8}$ It was initially thought that phenol selectively inhibits the interneural gamma efferent system which mediates muscle tone. ${ }^{5}$ Histological studies however, on animals as well as human nerve specimens and electron microscope studies indicated that phenol denatures any protein in contact. ${ }^{9,10}$

Phenol exerts two actions on nerves. ${ }^{11}$ Firstly, it has a short term effect similar to local anaesthetics, and is directly proportional to the thickness of the nerve fibres; secondly it has a long term effect related to protein denaturation. ${ }^{5}$ This leads to Wallerian degeneration of the axons. The long term effects of phenol motor point blocks depend on the latter. Mooney and associates studied the effect of phenol injection on the peroneal and tibial nerves of rabbits, ${ }^{10}$ and found that the degree of histological destruction was maximal after the second week. Burkell and $\mathrm{McPhee}^{9}$ showed that the maximal degree of neural damage was seen 2 weeks after the injection. Their study showed that the neural damage decreased with time, and complete regeneration occurred by the fourteenth week.

Khalili $^{3}$ pointed out that the average beneficial effect lasted 308 days and ranged from 2 days to 743 days. Awad ${ }^{4}$ reported that the duration of the effects of a block ranged from 3 to 14 months. Garland ${ }^{7}$ obtained almost the same results in hemiplegic patients.

Our subjects consisted of traumatic spinal cord injured patients, different to the above mentioned studies. Our best results were obtained by the end of the first week following phenol blockage. The beneficial effect appeared to decrease with time. At the end of the second month, the total number of patients with grades 4 and 5 spasticity was $20(12+8)$ among initially 
grade 5 patients, and $10(8+2)$ among initially grade 4 patients.

Although statistical analysis of the 50 patients shows a significant ongoing beneficial effect of the blockage, Table VI reveals that the total number of grade 4 and 5 spasticity patients rises to $30(20+10)$, while it is $17(10+7)$ at the end of the first month (Table V). One reason for this may be the diversity of the patients studied by Khalili $^{3}$, because they were both spinal injured and brain damaged patients. In his article he neither classified his subjects nor pointed out in which group of patients he obtained the best results. Garland's and Wainapel's patients were hemiplegics. ${ }^{7,8}$ Also, since our best results were obtained in the first week, this clinical picture was contrary to the histological changes. We conclude that phenol blocks have some beneficial effect on the spasticity of spinal cord injured patients on a temporary basis, and can be used as an adjunctive therapy without expecting long term effects.

\section{References}

1 Young RR, Allen WW (1987) Spasticity. Clin Orthop 219: 50-62.

2 Maynard FM, Karunas RS, Maring WP (1990) Epidemiology of spasticity following traumatic spinal cord injury. Arch Phys Med Rehabil 71: 556-569.

3 Khalili AA, Betts HB (1967) Peripheral nerve block with phenol in the management of spasticity. JAMA 200: $1155-1157$.

4 Awad EA (1972) Phenol block for control of hip flexor and adductor spasticity. Arch Phys Med Rehabil 53: 554-557.

5 Braun RM, Hoffer M, Mooney V, McKeever J, Roper B (1973) Phenol nerve block in the treatment of acquired spactic hemiplegia in the upper limbs. J Bone Joint Surg 55 A: 580-585.

6 Garland DE, Lucie RS, Waters RL (1982) Current uses of open nerve blocks for adult acquired spasticity. Clin Orthop 165: 217-222.

7 Garland DE, Menachem L, Keenan MA (1984) Percutaneous phenol blocks to motor points of spastic forearm muscles in head-injured adults. Arch Phys Med Rehabil 65: 243-245.

8 Wainapel S, Haigney D (1984) Spastic hemiplegia in a quadriplegic patient treatment with phenol nerve block. Arch Phys Med Rehabil 65: 786-787.

9 Burkel WE, McPhee M (1970) Effect of phenol injection into peripheral nerve of rat: electron microscope studies. Arch Phys Med Rehabil 51: 391-397.

10 Mooney V, Frykmang, McLamb J (1969) Current status of intraneural phenol injections. Clin Orthop 63: 122-131.

11 Felsenthal G (1974) Pharmacology of phenol in peripheral nerve blocks review. Arch Phys Med Rehabil 55: 13-16. 